\title{
Community/Agency Trust and Public Involvement in Resource Planning
}

\author{
JORDAN W. SMITH
}

Department of Forestry and Natural Resources, Purdue University, West Lafayette, Indiana, USA

\author{
JESSICA E. LEAHY
}

School of Forest Resources, University of Maine, Orono, Maine, USA

\section{DOROTHY H. ANDERSON}

Department of Parks, Recreation and Tourism Management, North Carolina State University, Raleigh, North Carolina, USA

\section{MAE A. DAVENPORT \\ Department of Forest Resources, University of Minnesota, St. Paul, Minnesota, USA}

\begin{abstract}
We hypothesize and test a positive relationship between the extent to which local community members trust a management agency and their willingness to engage in resource-related public discourse and involvement. We employ a multilevel generalized mixed model to analyze data collected from five different samples of residents living near managed resource areas. Counter to our proposed hypotheses, results suggest individuals' level of dispositional trust, their belief that management shares similar values as them, and their trust in the moral competency of the management agency were all found to be significantly and negatively related to public involvement in resource-related activities. These findings suggest that the central role of building trust among local constituents within many planning frameworks needs to be reconsidered with consideration given to both the needs of individuals who trust an agency and the desires of distrusting individuals who are more likely to become involved in public involvement efforts.
\end{abstract}

Keywords community/agency relationships, trust, watershed management

Many natural resource management agencies have adopted planning and management frameworks that attempt to build stronger, more reciprocal and mutually beneficial relationships with stakeholders and local community members. Theoretically, investing in social relationships will reduce expenditures in both time and money due to litigation or stalled planning efforts and ultimately lead to stable long-term

Received 3 May 2011; accepted 24 January 2012.

Address correspondence to Jordan W. Smith, FORS201A, 195 Marsteller Street, West Lafayette, IN 47907, USA. E-mail: smit1547@purdue.edu 
Table 1. Dimensions of community/agency trust

\begin{tabular}{|c|c|}
\hline Community/agency trust dimension & $\begin{array}{l}\text { Previous natural resource } \\
\text { management research }\end{array}$ \\
\hline Dispositional trust & Leahy and Anderson 2008 \\
\hline \multirow{11}{*}{ Trust in federal government } & Davenport et al. 2007 \\
\hline & Konisky et al. 2008 \\
\hline & Knopp and Caldbeck 1990 \\
\hline & Leahy and Anderson 2008 \\
\hline & Lubell 2004 \\
\hline & Mazur and Curtis 2006 \\
\hline & Palmer et al. 2009 \\
\hline & Poortinga and Pidgeon 2003 \\
\hline & Shindler et al. 1996 \\
\hline & Steel et al. 1994 \\
\hline & Stern 2008a, 2008b \\
\hline \multirow[t]{9}{*}{ Shared values } & Cvetkovich and Winter 2003 \\
\hline & Davenport et al. 2007 \\
\hline & Haight and Ginger 2000 \\
\hline & Leahy and Anderson 2008 \\
\hline & Lijeblad et al. 2009 \\
\hline & Needham and Vaske 2008 \\
\hline & Siegrist et al. 2000 \\
\hline & Stern 2008a, 2008b \\
\hline & Vaske et al. 2007 \\
\hline \multirow[t]{9}{*}{ Moral competency } & Davenport et al. 2007 \\
\hline & Jarmon 2009 \\
\hline & Leahy and Anderson 2008 \\
\hline & Payton et al. 2005 \\
\hline & Lachapelle et al. 2003 \\
\hline & McCool and Guthrie 2001 \\
\hline & Nie 2003 \\
\hline & Smith and McDonough 2001 \\
\hline & Stern 2008a, 2008b \\
\hline \multirow[t]{9}{*}{ Technical competency } & Davenport et al. 2007 \\
\hline & Haight and Ginger 2000 \\
\hline & Hartley and Robertson 2009 \\
\hline & Leahy and Anderson 2008 \\
\hline & Needham and Vaske 2008 \\
\hline & Nie 2003 \\
\hline & Palmer et al. 2009 \\
\hline & Stern 2008a, 2008b \\
\hline & Winter et al. 2004 \\
\hline
\end{tabular}

relationships between resource management agencies and local communities (Pretty and Ward 2001). One objective of management frameworks focused on building strong ties with local stakeholders is to encourage local residents to become aware of and involved in resource-related management and planning (Beierle and Cayford 
2002; Creighton 2005). In short, successful co-management of natural resources requires both proactive engagement efforts on the part of resource management agencies and reciprocal involvement in resource planning on the part of local community members (Berkes 2010). Despite this fact, relatively little empirical research has examined whether the trust held by local community members toward a resource management agency actually transfers into a citizenry more informed and involved in resource-related planning. We address this need through the guiding question of whether or not individuals' trust in a management agency is related to their involvement in resource-related planning. Specifically, we identify five dimensions of community/agency trust relationships (Table 1) - individuals' dispositional trust, their trust in the federal government, their belief the management agency shares values similar to theirs, their belief that the agency is morally competent, and their belief the agency is technically competent_which might influence individuals' willingness to engage in planning efforts. Our guiding hypothesis extends through each of these five dimensions as we examine the strength of relationships between these dimensions of trust and selected forms of individuals' involvement in resource-related planning.

\section{Dimensions of Community/Agency Trust}

\section{Dispositional Trust}

Individuals' general tendency to trust or distrust others, their dispositional trust, is a relatively stable personality characteristic that previous research suggests might affect the extent of trust placed in a resource management agency (Leahy and Anderson 2008; Scheufele and Shah 2000). The strength of an individual's dispositional trust is generally attributed to his or her early-life social interactions, which coalesce into a relatively stable personality characteristic (Rotter 1971). Some research suggests individuals' general disposition to trust others can be a significant predictor of trusting and risk-taking behaviors (Goto 1996).

Previous research has also illustrated how individuals' dispositional trust can influence their trust in a natural resource management agency. In interviews with local community members living near managed recreation areas in the midwestern United States, Leahy and Anderson (2008) found that when individuals lacked information and experience with the management agency they defaulted to their disposition toward society as a whole. For most individuals interviewed, this was a position of trust rather than distrust. This research also noted that if individuals had specific knowledge or experience with the agency, their willingness to trust the agency was based on that information, as opposed to their generalized beliefs.

\section{Trust in Federal Government}

Individuals' general level of confidence in the ability of the federal government to carry out its fiduciary responsibilities has also been identified as a contributing factor affecting the extent to which they trust a management agency. For example, research on the trust in government by local community members living near the Midewin National Tallgrass Prairie in Illinois managed by the USDA Forest Service found that several community members held a deep-seated distrust of government, which 
directly influenced those individuals' willingness to trust the agency in future management decisions (Davenport et al. 2007). Similar findings were reported in research concerning trust in the management of Great Smoky Mountains National Park in Southern Appalachia (Stern 2008b). Some previous research suggests that the influence individuals' trust in a federal government has on their trust in local resource management may be amplified within the United States, where individual autonomy and skepticism are relatively high (Steel et al. 1994); however, evidence also exists showing a similar relationship between trust in federal government and trust in resource management agencies from outside the United States (Mazur and Curtis 2007; Ohno et al. 2010).

\section{Shared Values}

A belief in shared values is one of the most commonly identified factors affecting individuals' trust in resource management agencies. The belief in shared values refers to individuals' perception of whether their perspectives, opinions, and desired outcomes regarding resource management are reflected in an agency's planning and management efforts. For example, Cvetkovich and Winter (2003) found a positive correlation between feelings of similar values toward threatened and endangered species and trust in the U.S. Forest Service among residents living near national forests in northern California. Similarly, previous research has found a significant and positive relationship between similar values toward wildfire management and trust in forest management agencies (Vaske et al. 2007). Finally, researchers have found that perceived similarity in values is positively related to trust in state wildlife management agencies (Needham and Vaske 2008). Collectively, this body of research on perceived similarity in values suggests it is a foundational component of trust in resource management agencies.

\section{Moral and Technical Competencies}

Several factors related to what an agency is obligated or expected to do-its perceived efficacy - have been identified in previous research. Specifically, Barber (1983) noted that for trust to exist in any relationship, there must be some expectation on the part of the trustor (e.g., local community member) that the trustee (e.g., management agency) will adhere to moral codes, show respect for the trustor's values, and be technically capable and able to perform specific tasks that yield benefits for the trustor. The former expectation refers to the beliefs about an individual's or agency's moral competency, while the latter expectation refers to its technical competency. In the resource management literature, numerous studies have found that local community members described their trust in a management agency as a product of whether or not that agency would make ethically grounded decisions (moral competence) guided by the best available scientific and technical knowledge (technical competence).

\section{The Effect of Trust on Public Involvement}

Many natural resource management agencies invest substantial time and resources into building trusting relationships with local community members in the hopes of producing more just and efficient resource planning processes (Rydin and Pennington 
2000). However, the influence of the trust held within these relationships on local community members' participation in resource-related actions has rarely been examined; the empirical work that has been conducted has yielded mixed results. In an examination of farmers' participation in a river management partnership in Florida, expected reciprocity and trust in local government were both found to positively and significantly influence participation in the partnership (Lubell 2004). However, farmers' trust in regulatory agencies, their trust in the farm industry, and their generalized trust in government were not found to influence participation. Other evidence has been found in a recent examination of local community members' participation in government-led activities and voluntary waterway cleaning efforts within the Yodo River watershed in Japan (Ohno et al. 2010). Researchers found individuals' level of dispositional trust did not influence participation in watershed management activities. In fact, one regression analysis suggested that higher levels of dispositional trust had a significant and negative influence on involvement in government-led watershed management activities. In another study examining the relationship between trust and participation in resource management-related activities, Payton, Fulton, and Anderson (2005) distinguished between "individual" and "institutional trust" among residents living near the Sherburne National Wildlife Refuge in Minnesota. Individual trust referred to feelings of reciprocity and community between respondents and others living near the refuge. The authors found this form of trust had a significant and positive influence on individuals' level of involvement in local resource planning and management efforts. Conversely, institutional trust referred to generalized trust in the management agency (the U.S. Fish and Wildlife Service) and its personnel. The authors found this form of trust unrelated to involvement in resource planning and management.

Previous research has identified consistent relationships among individuals' sociodemographic characteristics and their involvement in resource planning and management efforts (Mohai 1992; Ozanne et al. 1999; Stern et al. 1993). Generally, older, more educated, and wealthier individuals tend to be more involved in environmental management efforts than their counterparts; women also tend to be more civically involved in environmental efforts. Given the consistency of previous findings, we expect similar results in our analysis of public involvement.

Collectively, this growing body of literature suggests two things. First, there is no support for a consistent and significant relationship between individuals' generalized levels of trust (i.e., dispositional trust or trust in the federal government) and their willingness to become involved in either planning or management efforts. Second, there is little support for a consistent and significant relationship between individuals' trust in a resource management agency and their involvement in resource planning efforts. Only one study (Payton et al. 2005) found a significant and positive relationship. Given the inconsistency and paucity of previous research, we propose six hypotheses concerning the relationship between community/agency trust and public involvement outcomes.

\section{Hypotheses}

Based upon the previous research just outlined, we analyzed the following six hypotheses. Given the inconsistent findings of previous empirical research, the nature and direction of the relationships hypothesized here are consistent with predominating assumptions in contemporary natural resource management frameworks 
(i.e., trusting relationships lead to increased public involvement) (Kusel and Adler 2001; Schuett et al. 2001; Wondolleck and Yaffee 2000).

$\mathrm{H}_{1}$ : Individuals' level of dispositional trust will be significantly and positively related to the likelihood they will become involved in resource-related planning efforts.

$\mathrm{H}_{2}$ : Individuals' level of trust in the federal government will be significantly and positively related to the likelihood they will become involved in resource-related planning efforts.

$\mathrm{H}_{3}$ : The extent to which individuals believe a management agency shares similar values as themselves will significantly and positively influence the likelihood they will become involved in resource-related planning efforts.

$\mathrm{H}_{4}$ : The extent to which individuals believe a management agency is morally competent will significantly and positively influence the likelihood they will become involved in resource-related planning efforts.

$\mathrm{H}_{5}$ : The extent to which an individual believes a management agency is technically competent will significantly and positively influence the likelihood he or she will become involved in resource-related planning efforts.

$\mathrm{H}_{6}$ : Individuals' age, gender (female), education, and income will significantly and positively influence the likelihood they will become involved in resource-related planning efforts.

\section{Methods}

\section{Study Communities and Associated Resource Areas}

Data for this study were collected through questionnaires administered to residents living in five communities adjacent to four public-trust resource areas in the United States: Lake Shelbyville, Illinois; Carlyle Lake, Illinois; Navigation Project, Illinois; and Voyageurs National Park (VNP), Minnesota. The three Illinois resource areas are within the Kaskaskia River Watershed (KRW) and are managed by the U.S. Army Corps of Engineers (Corps), while the National Park Service manages Voyageurs National Park.

\section{Data Collection}

In the KRW, data were collected from a representative sample of residents living in communities within 15 miles of the three Corps projects. These sample frames were generated from tax records and addresses included in local phone number listings. Random samples of 533 households per resource area were selected to receive a mail-back questionnaire. Following the administration of the questionnaires according to the tailored design method (Dillman et al. 2008), 213 questionnaires were returned from respondents near Lake Shelbyville, 233 from respondents near Carlyle Lake, and 201 from respondents near Navigation Project. After subtracting undeliverable questionnaires $(65,41$, and 25 , respectively), the response rates were 46,45 , and $40 \%$, respectively. Nonresponse bias was checked using the extrapolation method of successive survey waves; no substantial results were found ${ }^{1}$ (Armstrong and Overton 1977). 
In the VNP study, the same sampling methodology was used. However, the VNP sample consisted of 575 households from each of the two study areas (International Falls and other surrounding communities). Totals of 313 and 297 questionnaires were returned from their respective samples. Subtracting undeliverable questionnaires (62 and 88 , respectively) yielded response rates of $61 \%$ for both samples. Nonresponse bias was also checked for the Voyageurs' sample by comparing summary statistics of selected demographic variables (gender, median age, median income, and educational level attained) of respondents with Census Bureau data for Koochiching County and St. Louis County, MN, in which VNP is located. ${ }^{2}$

\section{Measures}

Based upon our review of the literature and 31 interviews with community members living within the KRW (see Leahy and Anderson 2008) we developed a pool of 22 statements intended to measure the five dimensions of community/agency trust. Respondents were asked to indicate their level of agreement on a 5-point Likert-type scale ranging from 1 (strongly disagree) to 5 (strongly agree). Following methods for the development of valid psychometric scales (Bollen 1989; Clark and Watson 1995) we tested our community/agency trust measurement scale for reliability and construct validity (convergent and discriminant). This vetting process for appropriate psychometric properties yielded a 16-item community/agency trust scale intended to measure the five distinct dimensions of trust (Table 2).

Concurrently, we developed a pool of 10 items that inquired about whether or not local community members had been aware of or involved in a diverse array of resource planning efforts. These public involvement activities ranged from "reading or listening to news articles related to resource management and planning" to "writing a letter to a local newspaper regarding planning and management efforts." Respondents were asked to indicate (yes or no) whether they had ever engaged in each of the 10 activities (Table 3 ).

\section{Multilevel Structural Equation Modeling}

With the validity of our trust dimensions established, we examined their effect on individuals' public involvement in resource planning through a generalized multilevel structural equation model (Rabe-Hesketh et al. 2004a). These models were estimated using a generalized linear latent and mixed modeling (GLLAMM) framework. ${ }^{3}$ Multilevel structural equation models are composed of both a response model and a structural model. The response model is a generalized linear model specified through a linear predictor, a link, and a distribution from the exponential family. Given our public involvement statement items are dichotomous, we utilize a two-parameter logistic response model (2PL). The 2PL model is specified via a logit link and the binomial distribution; it is also a common model specified in applications of item-response theory (IRT) (Embretson 2010). The 2PL response model, illustrated in the right side of Figure 1, allows us to estimate the probability of an individual engaging in a particular action relative to his or her general level of public involvement (the latent variable, $\theta_{n}$, generated from the suite of public involvement items). Individual public involvement actions are treated as random effects and are nested within individuals. The primary advantage of this analytical approach is that it enables the estimation of a latent public involvement measure that (1) is unique to 


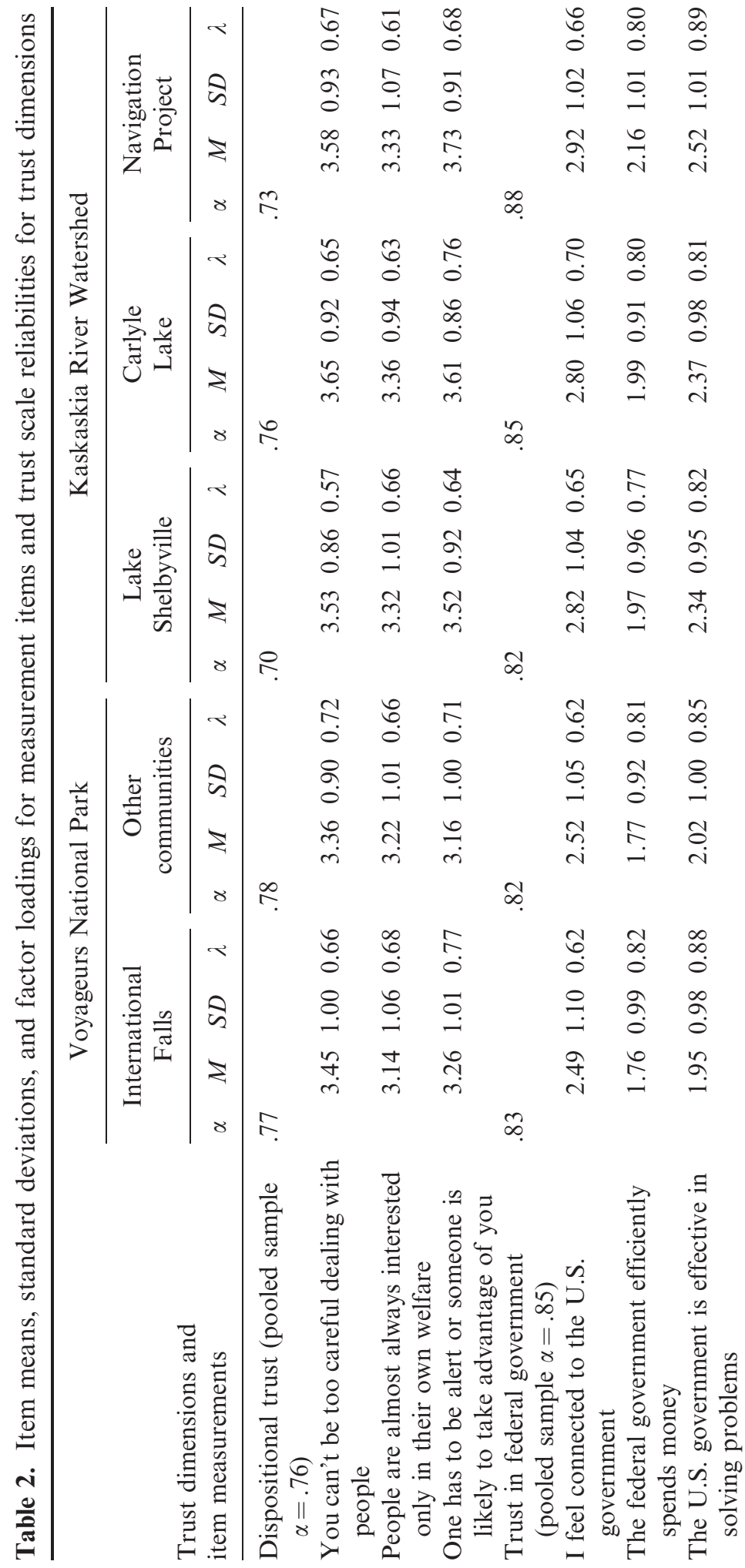




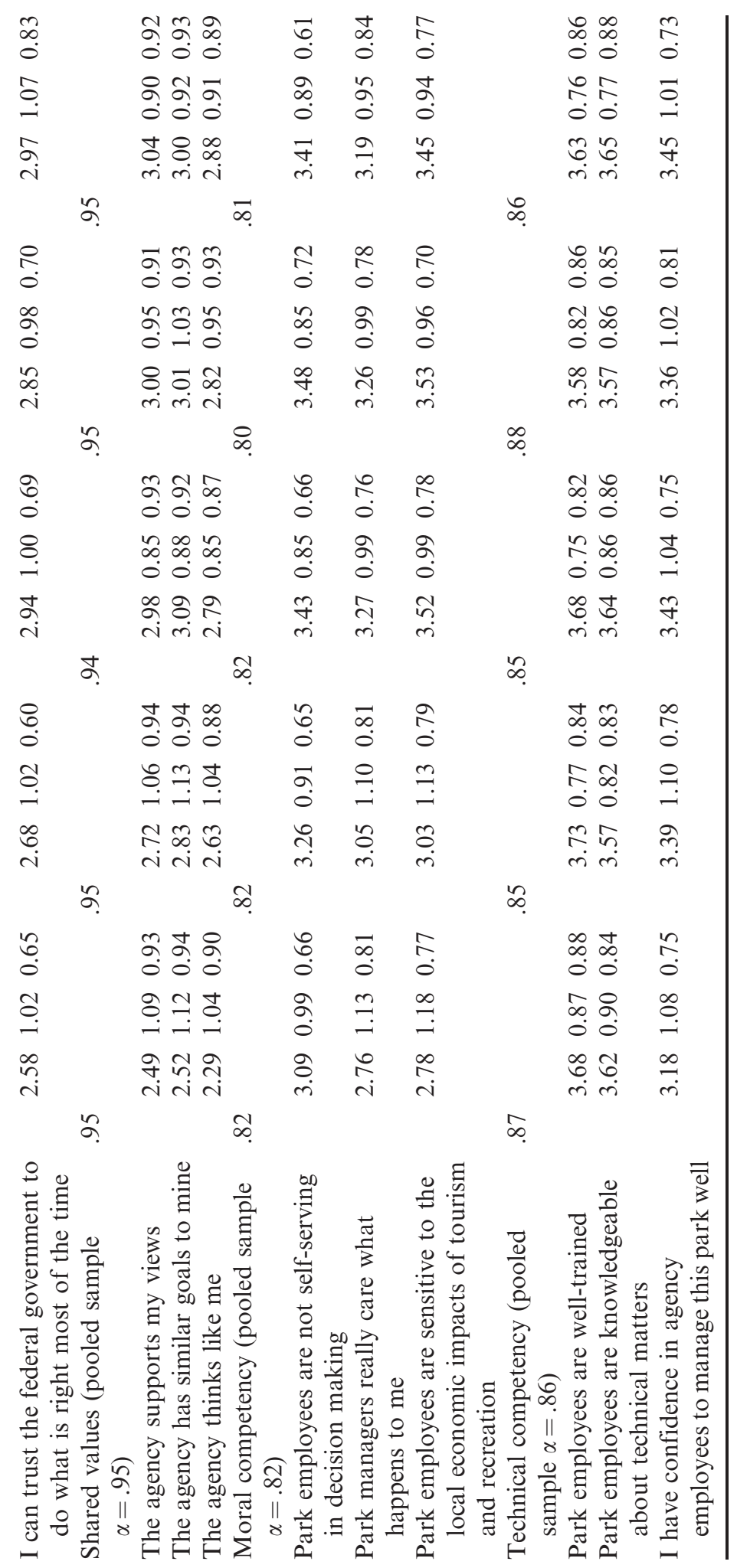




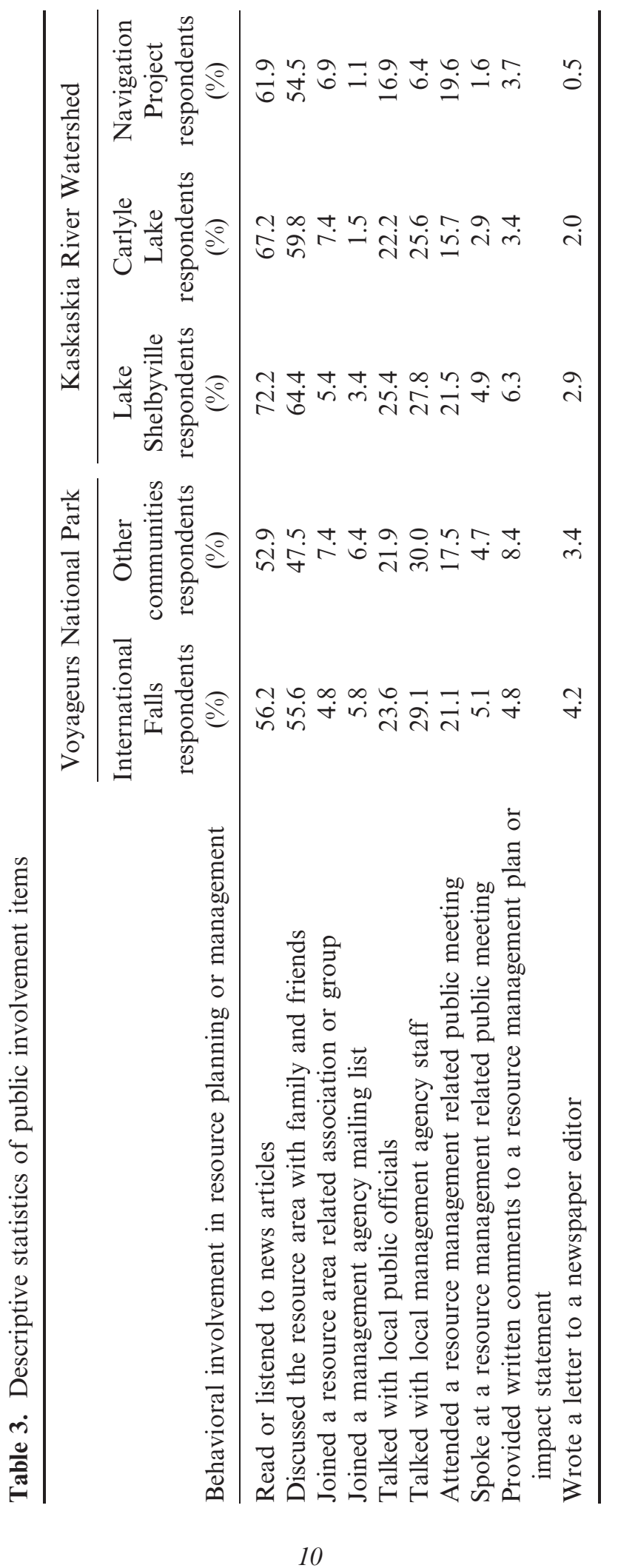




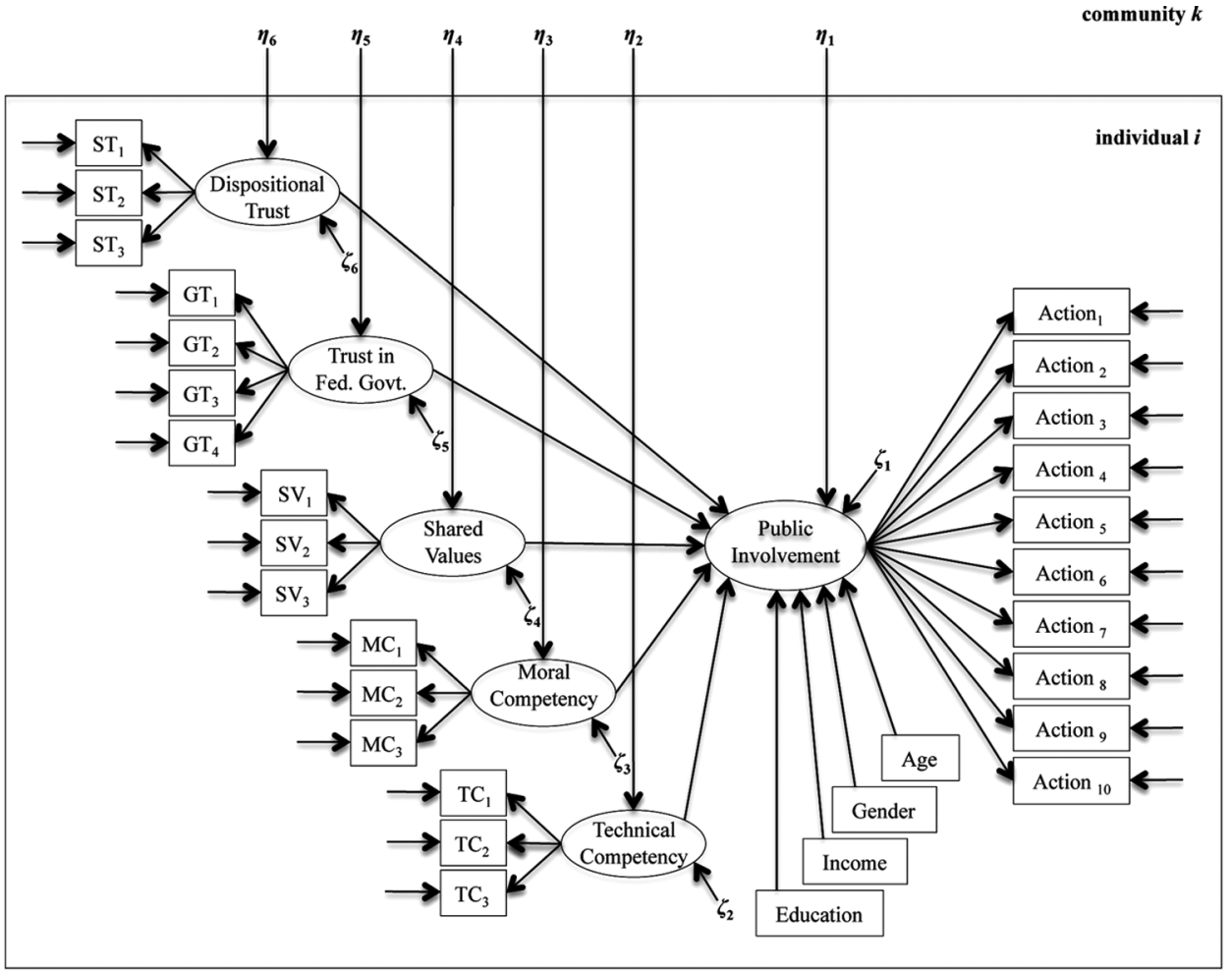

Figure 1. Community/agency trust and public involvement structural model (multilevel latent regression two-parameter logistic model).

each respondent and (2) discriminates public involvement actions relative to their difficulty. ${ }^{4}$ The latent public involvement measure, typically referred to as an "ability" parameter within IRT literature, is subsequently utilized as the dependent variable in estimation or the structural model. Being able to discriminate public involvement items relative to their difficulty is important because not all actions are equally demanding; for example, taking a stand in a resource planning meeting takes considerably more effort than just attending, which, in turn, is more difficult than just reading about the meeting in the local newspaper.

The structural model of a generalized multilevel structural equation model estimates the hypothesized relationships between multiple latent factors (ovals in Figure 1) as well as between latent factors and observed covariates (rectangles). For our latent variable, public involvement $(\theta)$ the structural model is defined as:

$$
\begin{aligned}
\theta_{n}= & \beta_{1} \text { DISPOSITIONALTRUST } \\
& +\beta_{2} \text { TRUSTINFEDERALGOVERNMENT } \\
& +\beta_{3} \text { SHAREDVALUES } \\
& +\beta_{4} \mathrm{MORALCOMPETENCE} \\
& +\beta_{5} \mathrm{TECHNICALCOMPETENCE}^{\prime} \\
& +\gamma_{1}^{\prime} \mathrm{AGE}_{n}
\end{aligned}
$$




$$
\begin{aligned}
& +\gamma_{2}^{\prime} \operatorname{GENDER}_{n} \\
& +\gamma_{3}^{\prime} \operatorname{EDUCATION}_{n} \\
& +\gamma_{4}^{\prime} \mathrm{INCOME}_{n}+\zeta_{n}
\end{aligned}
$$

where the subscript $n$ denotes individuals, $\beta$ denotes the regression parameter for each of the five latent trust variables, and $\gamma$ denotes the regression parameters for observed covariates. Finally, $\zeta$ denotes the disturbance parameters.

Given that our dependent variables within the response model are each of the public involvement items (binomial outcomes) and we also have individual and sample-level data, we chose to specify a multilevel model. Our specification has 12,070 individual public involvement measurement items (level 1 units) nested within 1,207 individuals (level 2 units) nested within 5 distinct study samples (level 3 units). The multilevel nature of our data and our generalized multilevel structural equation specification allow us to analyze all five samples simultaneously. By doing this, we can discern whether our findings are consistent across all five study areas, and therefore can be assumed to have more generalizability and validity.

\section{Results}

\section{Multilevel Two-Parameter Logistic Model}

Descriptive statistics illustrating the psychometric properties of our 16-item trust scale are presented in Table 2 for reference. We begin with the descriptive statistics for the 10 public involvement items (Table 3), which reveal a wide variety of actions that range from those most people had performed (e.g., reading or listening to news articles, $53 \%-72 \%$ of respondents) to those that were very infrequently done (e.g., writing a letter to a newspaper editor, $1 \%-4 \%$ of respondents). Given this large variation in levels of involvement, it would be prudent to examine the probabilities of performing each of the civic actions relative to individuals' general level of public involvement. The 2PL model, which we employed next, allows us to accomplish this.

The initial stage of our multivariate analysis involved just the response model comprised of the 10 observed public involvement measurement items and the latent public involvement variable (Figure 1). The $2 \mathrm{PL}$ model, ${ }^{5}$ which we used to analyze this response model, yields coefficient estimates for each public involvement action (Table 4); the more negative the coefficient, the easier the action, and vice versa for actions with positive coefficients. These coefficients ranged from -0.914 for "reading or listening to news articles" (the easiest action) to 6.536 for "writing a letter to a newspaper editor" (the most difficult).

Coefficient estimates from the response model become more illustrative through the use of item characteristic curves shown in Figure 2. The item characteristic curves illustrate the probability of performing each of the public involvement action ( $y$-axis) relative to individuals' overall level of public involvement (the latent variable $\theta$ on the $x$-axis).

\section{Multilevel Structural Equation Model}

Next we extended our multilevel 2PL model by including the five dimensions of trust as latent factors, as well as the four observed sociodemographic covariates, thus 


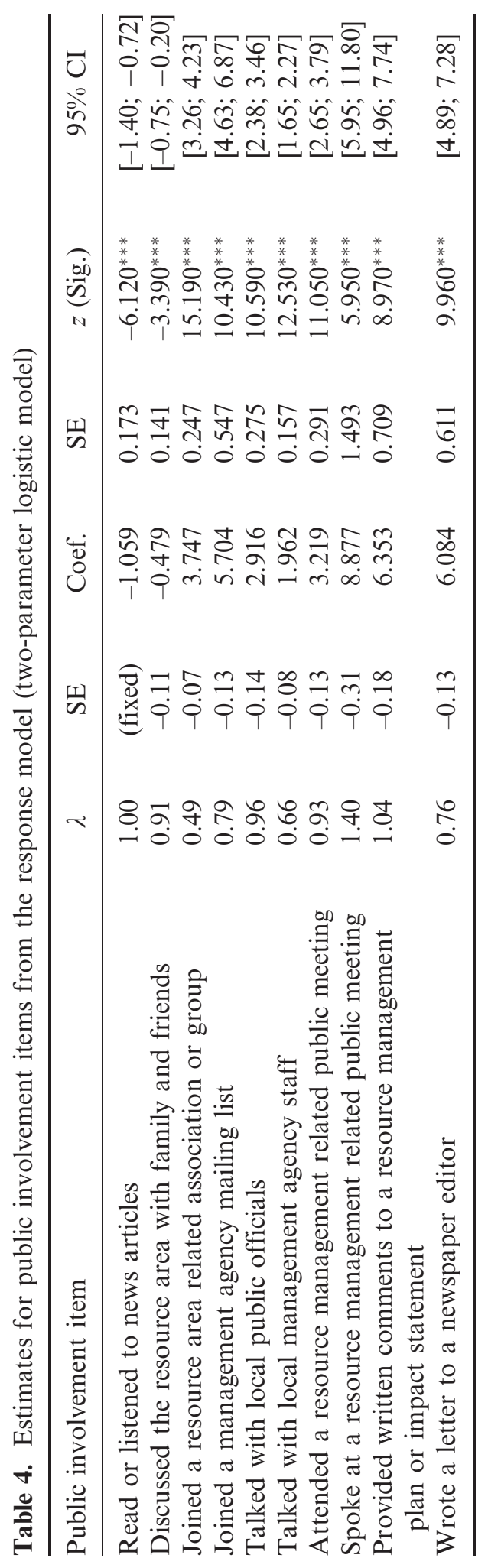




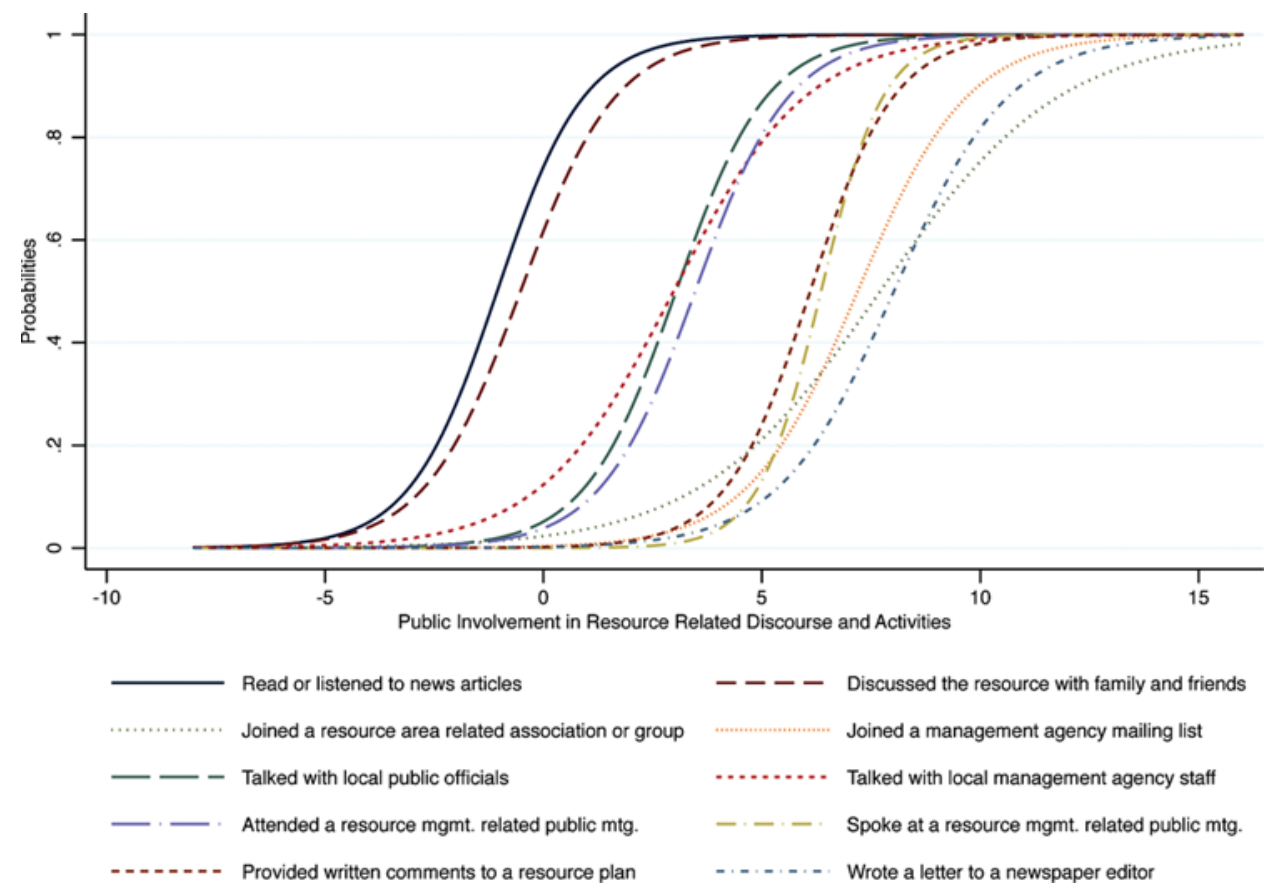

Figure 2. Probabilities of taking resource management related action relative to individuals' level of public involvement. (Color figure available online.)

Table 5. Estimates from the structural model (multilevel latent regression twoparameter logistic model)

Independent structural variables

\begin{tabular}{lrcrc}
\hline Trust dimensions (latent factors) & Coef. & SE & $p$ & $90 \%$ CI \\
\hline Dispositional trust & -0.485 & 0.034 & $<.001$ & {$[-0.55 ;-0.42]$} \\
Trust in federal government & 0.069 & 0.043 & .242 & {$[-0.03 ; 0.13]$} \\
Shared values & -0.122 & 0.053 & .032 & {$[-0.22 ;-0.01]$} \\
Moral competency & -0.101 & 0.047 & .050 & {$[-0.19 ; 0.00]$} \\
Technical competency & 0.025 & 0.035 & .496 & {$[-0.04 ; 0.09]$}
\end{tabular}

Sociodemographic characteristics (observed covariates)

\begin{tabular}{lrrcc} 
Age & 0.023 & 0.002 & $<.001$ & {$[0.02 ; 0.03]$} \\
Gender & -0.722 & 0.080 & $<.001$ & {$[-0.88 ;-0.57]$} \\
Education & 0.394 & 0.022 & $<.001$ & {$[0.35 ; 0.44]$} \\
Income & 0.079 & 0.016 & $<.001$ & {$[0.05 ; 0.11]$} \\
Within-subjects variance and covariance & Var. & Cov. & & \\
Individuals (level-two) & 5.440 & 0.576 & & \\
Study (level-three) & 0.008 & 0.054 & & \\
\hline
\end{tabular}

Note. The latent factor, public involvement, is the dependent structural variable. Adj. $R^{2}=14.41$. The Adj. $R 2=10.93$ when the latent trust factors are removed from the model. 
specifying the structural portion of our model ${ }^{6}$ The latent variable regression parameter estimates, $\beta \mathrm{s}$, as well as the covariate regression parameter estimates, $\gamma \mathrm{s}$, from the structural model are reported in Table 5.

Three of the five trust dimensions yielded significant relationships with individuals' general level of public involvement. The strongest relationship with public involvement in resource-related activities was the amount of trust individuals place in generalized others as a whole (dispositional trust, $\beta=-0.485, p<.001$ ). The direction and magnitude of this relationship suggest individuals who easily trust others are less likely to be civically involved in any of the resource-related activities asked about. Given this finding, we reject hypothesis 1.

The data also revealed a significant and negative relationship between individuals' belief that the resource management agency shared similar values as themselves and their level of engagement (shared values, $\beta=-0.122, p=.032$ ). The results reveal that if individuals believe either the Corps or the NPS held similar values as themselves, they were significantly less likely to become involved in resource-related activities. Given this finding, we reject hypothesis 3.

The final trust dimension that yielded a significant relationship with an individual's level of public involvement was moral competency. Similar to the dispositional trust and shared values dimensions, there was a negative relationship with public involvement $(\beta=-0.101, p=.050)$. Individuals who believed either the Corps or the NPS was morally competent to perform its duties and responsibilities were less likely to be civically engaged in resource-management efforts. Given this finding, we reject hypothesis 4 .

Finally, the results of our model suggest no relationship between either individuals' level of trust in the federal government as a whole or their trust in the technical competencies of resource management agencies and their level of involvement in resource-related activities. Given this finding, we fail to reject hypotheses 2 and 5.

All four of the sociodemographic covariates included in the model were significantly related to individuals' level of public involvement. More specifically, the data revealed that older individuals (age, $\beta=0.023, p<.001$ ) and women (gender, $\beta=-0.722, p<.001$ ) were more likely to be involved. Similarly, higher levels of educational attainment (education, $\beta=0.394, p<.001$ ) and income (income, $\beta=0.079$, $p<.001)$ were significantly and positively related to greater involvement in resource-related activities. Given these findings, we fail to reject hypothesis 6 .

\section{Discussion}

Our analysis of the trust in land managers held by community members living adjacent to public resource areas began with the objective of determining the extent to which five dimensions of community/agency trust were related to involvement in resource management activities. The analyses revealed several unique findings. First, the strongest influence on public involvement in resource-related activities was the amount of trust individuals place in generalized others as a whole (dispositional trust). Individuals who easily trust others were less likely to be involved in resource-related management actions. Second, the results showed a significant and negative relationship between individuals' belief that the resource management agency shared similar values as themselves and their level of involvement in resource-related activities. Finally, our analysis reveal a significant and negative relationship between individuals' level of involvement in planning and management efforts and their belief that 
the resource management agency is morally competent - that it will act in an ethical manner and consider how decisions could adversely affect local communities.

All three of these findings raise the same questions. Why are individuals with higher levels of these forms of trust less likely to be involved in resource management and planning efforts? If we accept that individual behavior is guided primarily by bounded rationality - the belief individuals' decisions attempt to maximize personal utility given a bounded decision-making environment - then these results become clearer (Jones 1999; 2001). Individuals who exhibit greater levels of trust, whether it be dispositional trust, shared values, or moral competency, do not feel the need to become involved in resource management decision because they already trust that the agency is looking out for their welfare. Previous research grounded within behavioral psychology suggests that trust is a key heuristic used when individuals are making decisions (Allison and Messick 1990). This line of theoretical reasoning suggests individuals' decision to participate (or not) in resource planning and management-related activities is based in part on whether or not they trust the resource management agency and its personnel. The more trust that individuals hold, the more likely they are to opt out of the opportunity to participate in resource-related discourse and involvement efforts. The data support the conclusion that individuals with greater levels of trust within each of the three significant dimensions believe the agency is capable of performing its duties and, therefore, does not need their involvement in planning or management efforts. Dissent over particular planning issues is likely to come from those individuals who do not trust an agency. And, as the data from this study illustrate, those individuals are exactly the ones most likely to be involved in resource planning efforts.

These findings suggest the central role of trust in natural resource planning and management efforts needs to be rethought, with attention given to the potential importance distrust plays in fueling public involvement in resource planning and management. Some research suggests distrust is essential to the continued functioning of modern social systems, as it encourages public discourse and representation in civic decision-making processes (Sunstein 2003; Warren 1999). This concept has been applied to resource management in an analysis of forest sector public advisory committees in Canada. Parkins (2010) suggests high levels of trust may, over time, reduce the effectiveness of democratic processes within resource planning and management frameworks. This discussion point highlights a unique complexity faced by federal natural resource management agencies. On one hand, they need to build trust with local community members to enable a more efficient planning processes and socially desirable outcomes. On the other hand, the strength and extent of that trust cannot come at the expense of democratic processes and the accommodation of dissent. As Webler and Tuler (2000) succinctly state, the challenge of decision-making processes is to "produce effective policy outputs while meeting the democratic expectations of all involved" (566-567).

Through these findings, a new light has been shed on the factors influencing local community members' trust in public trust resource management and how those factors affect the probability of individuals becoming involved in planning and management efforts. New questions have emerged, however, that deserve future consideration if a more complete understanding of trust and public involvement in natural resource science and management is to emerge. For example, the social relationship between an individual and a resource management agency is comprised of both cognitive (e.g., trust, beliefs, values) and structural (e.g., associational ties) components. Our 
analysis focused solely on the cognitive side of this relationship, as operationalized through the trust construct. However, the structural component of community/ agency relationships may also influence individuals' willingness, and ability, to become involved in resource planning efforts. For example, our analysis did not consider the number of planning meetings held or the number of resource-related groups through which individuals could get involved, if they chose to do so. These factors may moderate the relationship between cognitive components and public involvement. More specific, and comprehensive, research is warranted on the potential importance of the structural component of community/agency relationships on influencing public involvement.

\section{Notes}

1. Comparisons of the first and last waves of respondents on gender, education, income, and age showed no differences in the Lake Shelbyville and Navigation Project samples. In the Carlyle Lake sample, first-wave respondents differed from third-wave respondents on the amount of education obtained.

2. Significantly more males were sampled than females, but this difference may be related to property records used to obtain names and addresses of study participants. More males than females are listed as owning property. Surveys were mailed to the person on the property record but the surveys may have been filled out by another adult (spouse) living in the household.

3. We utilized the user-written command GLLAMM in the statistical package Stata 11.0 (see Rabe-Hesketh et al. [2004a, 2004b] for information on GLLAMM; also see Zheng and Rabe-Hesketh [2007] and Rabe-Hesketh et al. [2005] for information on the 2PL).

4. Frequently used maximum likelihood estimation of latent parameters using mainstream software programs (e.g., LISREL, AMOS) does not discriminate scale items, or public involvement actions in this case, against their relative degree of difficulty.

5. In the 2PL model (Birnbaum 1968), the probability of taking action on item $i$ by person $n$ is modeled as a function of an item parameter, $\delta_{i}$, representing the difficulty of that particular action, and a person parameter, $\theta_{n}$, representing the person's general level of public involvement. The additional slope parameter, $\lambda_{i}$, is referred to as a discrimination parameter, and determines how well action item $i$ "discriminates" across varying levels of public involvement, $\theta_{n}$. This probability is expressed as:

$$
\operatorname{Pr}\left(x_{i n}=1 \mid \theta_{n}\right)=\exp \left\{\lambda_{i}\left(\theta_{n}-\delta_{i}\right)\right\} / 1+\exp \left\{\lambda_{i}\left(\theta_{n}-\delta_{i}\right)\right\}
$$

6. Goodness of fit in generalized linear latent and mixed models is typically reported through log-likelihoods, Akaike information criterion (AIC), and Bayesian information criterion (BIC) statistics and is used to compare models. We also constructed a multigroup model, specifying distinct sample populations as groups, using maximum likelihood estimation to generate parameter estimates and more conventional model fit statistics. Given the complexity of our hypothesized model, we determined it adequately fit the data given the following fit statistics: $\chi^{2}=3363.11, d f=1410 ; \chi^{2} / d f=2.39$; RMSEA $(90 \% \mathrm{CI})=0.03$ $(0.03-0.04)$; $\mathrm{CFI}=.88 ; \mathrm{TLI}=.86$.

\section{References}

Allison, S. T., and D. M. Messick. 1990. Social decision heuristics in the use of shared resources. J. Behav. Decision Making 3:195-204.

Armstrong, J. S., and T. S. Overton. 1977. Estimating nonresponse bias in mail surveys. $J$. Market. Res. 14:396-402.

Barber, B. 1983. The logic and limits of trust. New Brunswick, NJ: Rutgers University Press. 
Beierle, T. C., and J. Cayford. 2002. Democracy in practice: Public participation in environmental decisions. Washington, DC: RFF Press.

Berkes, F. 2010. Devolution of environment and resource governance: Trends and future. Environ. Conserv. 37:489-500.

Birnbaum, A. 1968. Test scores, sufficient statistics, and the information structures of tests. In Statistical theories of mental test scores, ed. L. Lord and M. Novick, 424-435. Reading, MA: Addison-Wesley.

Bollen, K. A. 1989. Structural equations with latent variables. New York, NY: Wiley.

Clark, L. A., and D. Watson. 1995. Construct validity: Basic issues in objective scale development. Psychol. Assess. 7:309-319.

Creighton, J. L. 2005. The public participation handbook: Making better decisions through citizen involvement. San Francisco, CA: Jossey-Bass.

Cvetkovich, G., and P. Winter. 2003. Trust and social representations of the management of threatened and endangered species. Environ. Behav. 35:286-307.

Davenport, M. A., J. E. Leahy, D. H. Anderson, and P. J. Jakes. 2007. Building trust in natural resource management within local communities: A case study of the Midewin National Tallgrass Prairie. Environ. Manage. 39:353-368.

Dillman, D. A., J. D. Smyth, and L. M. Christian. 2008. Internet, mail, and mixed-mode surveys: The tailored design method, 3rd ed. Hoboken, NJ: John Wiley \& Sons.

Embretson, S. E., ed. 2010. Measuring psychological constructs: Advances in model-based approaches. Washington, DC: American Psychological Association.

Goto, S. G. 1996. To trust or not to trust: Situational and dispositional determinants. Soc. Behav. Personality 24:119-131.

Haight, D., and C. Ginger. 2000. Trust and understanding in participatory policy analysis: The case of the Vermont Forest Resources Advisory Council. Policy Stud. J. 28:739-759.

Hartley, T. W., and R. A. Robertson. 2009. Stakeholder collaboration in fisheries research: Integrating knowledge among fishing leaders and science partners in northern New England. Society Nat. Resources 22:42-55.

Jarmon, L. 2009. Displays of trust/mistrust in public meetings: "I don't believe you are going to jack us around!" Int. J. Public Participation 3:90-120.

Jones, B. D. 1999. Bounded rationality. Anпu. Rev. Polit. Sci. 2:297-321.

Jones, B. D. 2001. Politics and the architecture of choice: Bounded rationality and governance. Chicago, IL: University of Chicago.

Knopp, T. B., and E. S. Caldbeck. 1990. The role of participatory democracy in forest management. J. For. 88:13-18.

Konisky, D. M., J. Milyo, and L. E. Richardson Jr.. 2008. Environmental policy attitudes: Issues, geographic scale, and political trust. Soc. Sci. Q. 89:1066-1085.

Kusel, J., and E. Adler, eds. 2001. Forest communities, community forests: A collection of case studies of community forestry. Taylorsville, CA: Forest Community Research.

Lachapelle, P. R., S. F. McCool, and M. E. Patterson. 2003. Barriers to effective natural resource planning in a "messy" world. Society Nat. Resources 16:473-490.

Leahy, J. E., and D. H. Anderson. 2008. Trust factors in community-water resource management agency relationships. Landscape Urban Plan. 87:100-107.

Lijeblad, A., W. Borrie, and A. Watson. 2009. Determinants of trust for public lands: Fire and fuels management on the Bitterroot National Forest. Environ. Manage. 43:571-584.

Lubell, M. 2004. Collaborative watershed management: A view from the grassroots. Policy Stud. J. 32:341-361.

Mazur, N. A., and A. L. Curtis. 2006. Risk perceptions, aquaculture, and issues of trust: Lessons from Australia. Society Nat. Resources 19:791-808.

McCool, S. F., and K. Guthrie. 2001. Mapping the dimensions of successful public participation in messy natural resource management situations. Society Nat. Resources 14:309-323.

Mohai, P. 1992. Men, women, and the environment: An examination of the gender gap in environmental concern and activism. Society Nat. Resources 5:1-19. 
Needham, M. D., and J. J. Vaske. 2008. Hunter perceptions of similarity and trust in wildlife agencies and personal risk associated with chronic wasting disease. Society Nat. Resources 21:197-214.

Nie, M. 2003. Drivers of natural resource-based political conflict. Policy Sci. 36:307-341.

Ohno, T., T. Tanaka, and M. Sakagami. 2010. Does social capital encourage participatory watershed management? An analysis using survey data from the Yodo River Watershed. Society Nat. Resources 23:303-321.

Ozanne, L. K., C. R. Humphrey, and P. M. Smith. 1999. Gender, environmentalism, and interest in forest certification: Mohai's paradox revisited. Society Nat. Resources 12:613-622.

Palmer, S., F. Fozdar, and M. Sully. 2009. The effect of trust on West Australian farmers' responses to infectious livestock diseases. Sociol. Ruralis 49:360-374.

Parkins, J. R. 2010. The problem with trust: Insights from advisory committees in the forest sector of Alberta. Society Nat. Resources 23:822-836.

Payton, M. A., D. C. Fulton, and D. H. Anderson. 2005. Influence of place attachment and trust on civic action: A study at Sherburne National Wildlife Refuge. Society Nat. Resources 18:511-528.

Poortinga, W., and N. F. Pidgeon. 2003. Exploring the dimensionality of trust in risk regulation. Risk Anal. 23:961-972.

Pretty, J., and H. Ward. 2001. Social capital and the environment. World Dev. 29:209-227.

Rabe-Hesketh, S., A. Skrondal, and A. Pickles. 2004a. Generalized multilevel structural equation modeling. Psychometrika 69:167-190.

Rabe-Hesketh, S., A. Skrondal, and A. Pickles. 2004b. GLLAMM manual. University of California, Berkeley, Division of Biostatistics Working Paper Series. Berkeley: University of California, Berkeley.

Rabe-Hesketh, S., A. Skrondal, and A. Pickles. 2005. Maximum likelihood estimation of limited and discrete dependent variable models with nested random effects. J. Econometrics 128:301-323.

Rotter, J. B. 1971. Generalized expectancies for interpersonal trust. Am. Psychol. 26:443.

Rydin, Y., and M. Pennington. 2000. Public participation and local environmental planning: The collective action problem and the potential of social capital. Local Environ. 5:153-169.

Scheufele, D. A., and D. V. Shah. 2000. Personality strength and social capital-The role of dispositional and informational variables in the production of civic participation. Commun. Res. 27:107-131.

Schuett, M. A., S. W. Selin, and D. S. Carr. 2001. Making it work: Keys to successful collaboration in natural resource management. Environ. Manage. 27:587-593.

Shindler, B., B. Steel, and P. List. 1996. Public judgments of adaptive management: A response from forest communities. J. For. 94:4-12.

Siegrist, M., Cvetkovich, G., and C. Roth. 2000. Salient similarity, social trust, and risk/ benefit perception. Risk Anal. 20:353-362.

Smith, P. D., and M. H. McDonough. 2001. Beyond public participation: Fairness in natural resource decision making. Society Nat. Resources 14:239-249.

Steel, B. S., N. P. Lovrich, and J. C. Pierce. 1994. Trust in natural resource information sources and postmaterialist values: A comparative study of U.S. and Canadian citizens in the Great Lakes area. J. Environ. Syst. 22:123-136.

Stern, M. J. 2008a. Coercion, voluntary compliance and protest: The role of trust and legitimacy in combating local opposition to protected areas. Environ. Conserv. 35:200-210.

Stern, M. J. 2008b. The power of trust: Toward a theory of local opposition to neighboring protected areas. Society Nat. Resources 21:859-875.

Stern, P. C., T. Dietz, and L. Kalof. 1993. Value orientations, gender, and environmental concern. Environ. Behav. 25:322-348.

Sunstein, C. R. 2003. Why societies need dissent. Cambridge, MA: Harvard.

Vaske, J. J., J. D. Absher, and A. D. Bright. 2007. Salient value similarity, social trust and attitudes toward wildland fire management strategies. Hum. Ecol. Rev. 14:223-232. 
Warren, M. E., ed. 1999. Democracy and trust. Cambridge, UK: Cambridge University Press. Webler, T., and S. Tuler. 2000. Fairness and competence in citizen participation: Theoretical reflections from a case study. Admin. Soc. 32:566-595.

Winter, G., C. A. Vogt, and S. McCaffrey. 2004. Examining social trust in fuels management strategies. J. For. 102:8-15.

Wondolleck, J. M., and S. L. Yaffee. 2000. Making collaboration work: Lessons from innovation in natural resource management. Washington, DC: Island Press.

Zheng, X., and S. Rabe-Hesketh. 2007. Estimating parameters of dichotomous and ordinal item response models with GLLAMM. Stata J. 7:313-333. 